\title{
Una mirada a los (des)encuentros culturales en las relaciones de conflicto entre empresas mineras y poblaciones campesinas en el Perú
}

\author{
Juan Rodríguez Castillón \\ juanroca57@yahoo.com \\ Universidad Nacional Federico Villarreal
}

\begin{abstract}
Resumen
En el presente artículo se intenta comprender los desencuentros culturales entre empresas mineras y comunidades campesinas en el contexto de los conflictos mineros desarrollados en varios lugares del Perú. De esta manera este artículo describe y analiza algunos de ellos, exponiendo las causas de su estallido, así como también proponiendo tomar en consideración la dimensión intercultural para intentar solucionar los conflictos mineros.
\end{abstract}

Palabras clave: Conflicto agro-minero, comunidades campesinas, interculturalidad, cultura.

\begin{abstract}
The following article intend to understand the cultural conflicts between mine companies and farmer communities in the context of mine conflicts developed in several Peruvian place. In this way this article describes and analyzes some of them, showing the causes of its origin; in addition, it take consideration in the intercultural dimension in order to intend to solve this mine conflicts.
\end{abstract}

Keywords: Farmer-mine conflicts, farmer communities, intercultural, culture.

En gran parte de la década del 90 el sector minero tuvo una etapa de expansión. Aparecen nuevos polos geográficos de desarrollo minero. Así, el área ocupada por la minería en el territorio peruano creció de manera significativa. Esta expansión consolida la presencia de la minería en zonas tradicionales con esa actividad (como Junín, Pasco, Moquegua, Tacna, etc.) al mismo tiempo que la proyecta a otras zonas rurales sin experiencia minera, como las del departamento de Ancash, Cajamarca, La Libertad, Apurímac (De Echave y Torres 2005: 51). Es decir, se expanden a zonas de carácter rural en las que predominan las actividades 
agropecuarias, siendo las comunidades campesinas ${ }^{1}$ las directamente involucradas; en este contexto son inevitables las relaciones entre las empresas mineras y las comunidades, pero estas relaciones -en muchos casos- tienen un carácter conflictivo. El principal conflicto que enfrentan los agentes extractivos es con las poblaciones campesinas, ubicadas en el entorno de sus actividades, por el uso y control de los recursos naturales, a diferencia de lo que ocurrió en las décadas del 70 y 80 cuando el principal conflicto fue laboral, de mejoras salariales y condiciones de vidas.

En estos desencuentros se manifiestan intereses y valores económicos-culturales distintos entre las empresas mineras, el Estado y las poblaciones campesinas. Por un lado, tanto el Estado como las empresas mineras -inmersos en una visión cortoplacista, concepción desarrollista y eurocéntrica- buscarían maximizar la explotación minera del subsuelo visto como producto mercantil asociado a un valor de cambio y uso. Por otro lado, las poblaciones campesinas - lejos de una visión cortoplacista- tienen un tipo diferente de relación con los recursos de su entorno.

Es sobre los desencuentros culturales entre las empresas mineras y poblaciones campesinas que se reflexionará en este trabajo, intentando dar algunos alcances del por qué se produce el estallido de un conflicto minero y cómo se podría alcanzar el manejo del mismo. Para lograr nuestro cometido nos serviremos del caso del conflicto minero sucedido en Tambogrande, en la región de Piura, y además se mencionará otros de manera general.

\section{Panorama general de los conflictos mineros en el Perú}

Como se mencionó, en la introducción, hay una expansión de la actividad minera -comenzada a comienzos de la década del 90- y una importancia de la misma en la economía del Perú. Por ejemplo el INEI, en su informe técnico coyuntural de la actividad económica del Perú para el mes de abril del 2007, destaca el crecimiento de la actividad minera e hidrocarburos en $2.33 \%$ con respecto al mismo mes del año $2006^{2}$. Por su parte el Ministerio de Energía y Minas destaca, en su nota de prensa del mes de junio y julio del 2007, la contribución de divisas y el volumen de exportación del sector minero. Basándose en datos del BCR, el ministerio informa que el monto de las exportaciones mineras del 2007 representa el $62 \%$ del total de las exportaciones peruanas ${ }^{3}$. Los minerales son embarcados en dirección al mercado chino, USA, Suiza y Alemania donde tienen gran demanda.

A partir del 2003, bajo la influencia de un nuevo escenario favorable, se produce una recuperación en los niveles de inversión en el sector minero con la puesta en marcha de proyectos como el Alto Chicaza, Carachugo y la transferencia del proyecto Las Bambas en Apurimac. Así mismo, los niveles de inversión en exploraciones mineras se recuperaron, lo cual se reflejó en el aumento de petitorios mineros en un $60 \%$ en relación con el año precedente (De Echave y Torres 2005: 51). Según Clotilde Gouley, un marco legal propicio y condiciones geológicas favorables, han hecho que el sector minero registre en los últimos años un crecimiento superior al ritmo de la economía peruana, atrayendo cada vez más inversiones extranjeras y que en los últimos años representaron el $30 \%$ del total de las inversiones extranjeras captadas por el Perú (2005: 17). Agregando a lo que dice la autora, habría de afirmar que la coyuntura internacional de alza de los precios de los minerales

1 Según De Echave, J. en el Perú los territorios de las comunidades campesinas representan el 39\% de la superficie agropecuaria de todo el país y de las 5680 comunidades reconocidas y con títulos de propiedad, 3126 (es decir, el $55 \%$ del total) se encontraban a finales de la década pasada en zonas de influencia de la minería (2005, p. 52).

2 En http:// www.inei.gob.pe/web/notaprensa/attach/6884.pdf,

3 En http://intranet.minem.gob.pe/AppWeb/AppIntranet/Notihoy/notihoy_3406.pdf 
como la creciente demanda de los países industrializados, son factores que, también influyen para que el sector minero tenga un cierto dinamismo en el Perú.

No obstante, a pesar de tener un significativo protagonismo en la economía peruana, el desarrollo de la actividad minera, sobre todo en los últimos años del presente siglo, se ha visto plagado por escenas de conflictos que se han repetido uno tras otro en varios lugares del Perú. Sin lugar a dudas el principal conflicto que han enfrentado las empresas mineras ha sido con las poblaciones campesinas. Así, repasando brevemente, tenemos:

1. El sur. En Espinar (Cusco) los comuneros de varias comunidades (entre ellas Tintaya Marquiri) protestaron en el año 2001 contra las actividades de la empresa Minera BHP Billiton Tintaya S.A. El motivo: reclamos de tierras de las comunidades que habían sido expropiadas directamente por el Estado peruano y comprado inadecuadamente por la empresa minera. Esto significó que las comunidades campesinas (son cinco: Tintaya Marquiri, Huano Huano, Alto Huarca, Alto Huancane y Bajo Huancané), del entorno a la actividad minera, perdieran una cantidad importante de sus tierras. Según De Echave y Torres, los procesos de compras de tierras, que se realizaron en 1996, originaron situaciones de conflicto entre la empresa y las comunidades del entorno, quienes reclamaron la validez de las transacciones realizadas y los impactos ambientales que habían generado las operaciones de la mina (2005: 60).

También tenemos el caso de Las Bambas, ubicada en las provincias andinas de Cotabambas y Grau (Apurímac), ampliamente estudiado por Clotilde Gouley. En el mencionado lugar se desarrolló el proyecto Las Bambas, con lo cual son 49 las comunidades que se encontraron afectadas. Según la anterior autora, a veces denominada "la nueva Antamina", el proyecto, si bien todavía para el 2004 en su fase de exploración (prevista en ese entonces para 4 años), genera a la vez expectativas y temores avivados por un clima de desconfianza general en el Perú frente a la minería y sus impactos (Gouley 2005: 20).

En sus trabajos de campo, Gouley encuentra que gran parte de la población, frente al proyecto, se sentía excluida del proceso de decisión y sobre todo que tenían una situación de desequilibrio en el acceso a la información. Es por estas razonas que, en varias ocasiones, realizan acciones colectivas de protestas como las de agosto y septiembre del 2004, demandando mayor información y consulta popular sobre el proyecto.

Por último, en el distrito de Secclla de Angaraes, en Huancavelica, a mitad del 2002 la población empezó a alarmarse por evidencias de contaminación en sus ríos a causa de las actividades mineras de las empresas Pampali y American Gold. Esto generó relaciones ásperas entre la empresa y la comunidad.

2. El nor-centro. El centro del país es una zona con experiencia minera. Sin embargo, no son ausentes los desencuentros entre empresas mineras y poblaciones locales. Así, por un lado, tenemos que en los últimos años en Junín los pobladores de comunidades cercanas al lago Chinchaycocha protestaron por la contaminación de los humedales por desechos mineros ácidos y metales pesados que ponían en peligro la sobrevivencia de varias especies de aves acuáticas. Por otro lado, en el llamado norte chico, en San Marcos (Ancash), los comuneros del caserío de Chipta-Pincullo en varias ocasiones se enfrentaron a la minera Antamina por la contaminación ambiental en su zona y por que la minería no ha logrado mejorar los niveles de pobreza e impulsar un desarrollo sostenible en su localidad. Es decir, como dice Patricia Zárate y Anahí Durand, la relación entre minería y desarrollo sería distante, estando más cercana la actividad minera de perjudicar a los más pobres que de ayudarlos, dado que ocasiona pérdidas que no revierten en nuevos beneficios (Zárate y Durand 2005: 119, 123). 
3. El norte. Considerada como nueva zona en donde se ha desarrollado proyectos mineros.

Por una parte, en Cajamarca, en agosto del 2004, mediante una movilización multitudinaria los pobladores se manifestaron en contra de las actividades de la minera Yanacocha que pretendía realizar su actividad en el cerro Quilish, donde se encontraba un recurso de vital importancia para los cajamarquinos: el agua (por efectos de la minería implicaba afectar su calidad y cantidad). Por otra parte, en el departamento de Piura, tenemos el caso de varias comunidades de las provincias de Huancabamba y Ayabaca, donde en el 2001 la población organizada le dijo “basta a la mina Majaz”. En estas provincias son varias las comunidades altoandinas implicadas en el proyecto minero "Río Blanco", a cargo de la empresa china Zijin Mining. Tomando el ejemplo del distrito de Tambogrande (Piura), se llevó a cabo, en esas provincias, una consulta vecinal ${ }^{4}$ para que la población se pronuncie a favor o en contra del mencionado proyecto. El resultado fue que un $95 \%$ de la población dijeron $N o$, al proyecto Río Blanco.

En este mismo departamento -considerada como un caso emblemático de resistencia a la puesta en marcha de un proyecto minero- se encuentra el caso de Tambogrande, ubicado en el Valle de San Lorenzo, cuyos pobladores -básicamente agricultores campesinos- se manifestaron colectivamente en contra de la ejecución del proyecto minero de la empresa Canadiense Manhattan Minerals, con lo cual se llegó a emplear un tipo de violencia directa: destrucción de la infraestructura de la empresa hasta lograr que se retire de su territorio. Nos centraremos en este caso en el marco de exponer las causas del estallido de un conflicto minero y dar algunas ideas para el manejo del mismo.

\section{El conflicto minero en Tambogrande, Piura}

Tambogrande es un distrito compuesto por agricultores campesinos, ubicado en el valle de San Lorenzo (Piura). El conflicto tiene su antecedente histórico en 1980, durante el segundo gobierno de Fernando Belaúnde, cuando el entonces Ministro de Energías y Minas, Pedro Pablo Kuzcynski, quiso desarrollar la actividad minera en la zona. Mediante un Decreto Supremo se autorizaba a la empresa francesa BRGM, efectuar estudios de exploración en Tambogrande, sin embargo fue rechazado por la población.

En 1999 se inicia nuevamente el conflicto, al aprobarse y autorizarse, por parte del estado peruano, la concesión de derechos, acciones de minas y recursos complementarios a la compañía minera Manhattan en los terrenos de Tambogrande, en cuyo subsuelo se encontraban recursos polimetálicos (como el oro, zinc), lo cual significaba que, en la fase de exploración, se tenía que reubicar a la mitad del pueblo y excavar en un porcentaje del terreno con cultivos de frutas (Mangos, limón).

El conflicto continúa hasta fines del 2003. En el transcurso de 1999 al 2003 sucedieron varias acciones de luchas colectivas de los agricultores campesinos. Por ejemplo, el 27 y 28 de febrero del 2001 se paraliza Tambogrande, bloqueándose las principales vías de acceso y destruyéndose la infraestructura ${ }^{5}$ de la empresa. Otra acción colectiva la encontramos en noviembre del 2003, en que más de 7000 agricultores realizaron una huelga de tres días en contra de la audiencia pública sobre la mina realizado en el distrito de Piura.

4 El mecanismo de consulta es un medio para que la población se exprese ante las autoridades centrales, empresas mineras, antes de la ejecución de proyectos de gran envergadura. Sin embargo, el derecho de consulta y el resultado del mismo, no es reconocido por la autoridad central.

5 En vista de que parte de la actividad minera se iba ha realizar en el terreno donde se ubicaba la población, la minera decidió reubicarlos a otra parte, instalando, para ello, viviendas provisionales. No obstante, estas fueron destruidas así como las maquinarias, computadoras y mobiliarios de la Manhattan. 
En esta parte es necesario mencionar a los actores. Se puede identificar dos: uno de carácter local y el otro extralocal. En el primero, se encontraban los agricultores organizados en el Frente de Defensa y La Asociación Local de Productores de Mangos dirigido por Godofredo García Baca ${ }^{6}$; y al municipio distrital de Tambogrande que, en un primer momento, tuvo una posición a favor del proyecto minero. En relación al segundo, los actores son instituciones externas como la CONACAMI, Ongs, entre otras, que de alguna manera intervinieron en el conflicto. Gina Alvarado menciona que, en este nivel, los actores se dividen en los que apoyan al proyecto minero - como la Cámara de Comercio de Piura, universidades-y los que están a favor del desarrollo de la agricultura. En este último grupo destacan la presencia de ongs tanto de Piura (como Cipca, Piura Vida Agro, todas ellas agrupadas en el colectivo de apoyo a Tambogrande) como de Lima, entre las que están Cooperación, Cepes, Oxfam, entre otras. Todas ellas agrupadas en el colectivo de apoyo de Lima cuyas acciones consistieron en pronunciamientos, participación en foros, publicación de documentos y elaboración de estudios técnicos sobre el impacto de la minería y la valorización del valle de Tambogrande (Alvarado 2002: 164-171).

El municipio de Tambogrande, que por falta de una posición establece, tuvo una precaria legitimidad ante la población que esperaba un rol protagónico en la representación del pueblo. En un primer momento tuvo una posición expresa de apoyo al proyecto minero, después cambió hacia una oposición completa. En este segundo momento es cuando el municipio, con el apoyo del Frente de Defensa, convoca en junio del 2002 a una consulta vecinal $^{7}$ para que la población exprese su acuerdo o desacuerdo a que se desarrolle la actividad minera en el valle de Tambogrande.

La organización de esta consulta, paradigma para otras poblaciones con problemas similares $^{8}$, constituye un momento determinante del conflicto, ya que el $98 \%$ de la población rechazaba el proyecto minero, frente a un $2 \%$ que lo aprobaba. ¿Qué nos dice esta cifra?, que la casi totalidad de los agricultores campesinos del valle de Tambogrande defendieron la continuidad de un modelo de desarrollo basado en la agricultura, lo cual está relacionado con el particularismo económico local que -como veremos- se constituyó a lo largo de la historia del distrito y del valle de San Lorenzo. Pero, ¿cuál es la razón del estallido del conflicto?

\section{Una aproximación a las causas del conflicto minero en Tambogrande}

En realidad son varios los factores que acarrearon el conflicto. Alvarado menciona, como punto central, que el conflicto en Tambogrande es un proceso en el que confluyen factores como: 1) La centralización de la toma de decisiones por el Estado y asignación de recursos presupuestarios, 2) La ausencia del tratamiento del desarrollo rural sostenible y equilibrado, 3) La ausencia de mecanismos de participación ciudadana y, 4) La falta de consideración de los particularismos y heterogeneidades locales (Alvarado 2002: 149).

Estableciendo niveles de jerarquización entre los factores mencionados por Alvarado, podemos afirmar que la centralización de la toma de decisiones por el Estado es la más

6 Godofredo, principal líder agricultor, defensor del medio ambiente, contaba con una ONG “Trópico Seco". Llegó a constituir una amenaza para la Manhattan. Luego sería asesinado por desconocidos.

7 La realización de esta consulta se basaba en la Ley Orgánica de Municipalidades $\mathrm{N}^{\circ} 23853$, que establece como competencia de la autoridad municipal promover los mecanismos de participación de la población en el desarrollo de la comunidad; y, la Ley de Derechos de Participación y Control Ciudadano No 26300, que prevé la promoción de participación ciudadana a nivel municipal.

8 Puesto que sirvió de modelo para que en otras partes del mundo se llevara a cabo una consulta sobre minería. El ejemplo es la comunidad de Esquel -un pueblo agrícola y pesquero de Patagonia en Argentina- que, al tener problemas con una compañía minera, desarrolla en el 2003 un referendo cuyo resultado fue que más del $80 \%$ de la población votó en contra de la realización del proyecto minero. 
influyente, en la medida en que algunos de los otros factores aparecen a raíz del primero. Es decir, el hecho de que una de las partes tome una decisión centralizada conlleva a excluir de la participación a la otra parte, a su vez que implica no tomar en consideración los particularismos culturales locales. En este sentido, vamos a subrayar la centralización de la toma de decisiones por el Estado peruano al conceder los derechos de minas a la compañía minera Manhattan en el valle de Tambogrande, sin consultar a los pobladores a través de sus representantes. La presencia del factor mencionado ocasionó la resistencia de los agricultores campesinos y defensa de un modelo de desarrollo basado en la agricultura, en torno a la cual gira la totalidad de sus modos de vidas - que viene a ser cultural-; y permite la reproducción de la sociedad local, al ser la principal fuente de recurso económico. Esto nos lleva a afirmar lo siguiente: que en el conflicto agrominero en Tambogrande estuvo en juego tanto el interés cultural como económico.

Por el lado cultural, que vendría a ser la parte invisible del conflicto, como se demuestra en el siguiente testimonio de un campesino agricultor de Tambogrande:

“...nosotros somos agricultores, no somos mineros...es gente que tiene una identidad, tiene un sentimiento por su agricultura" $"$

Nótese el sentido de pertenencia: la identidad está asociada a la actividad agraria. Con esto, se puede afirmar que los agricultores campesinos defendieron una identidad cultural y un modo de vida basado en la actividades agrícola, la cual se ponía en riesgo con la llegada de la minería; ya que, en vista de que una parte del mineral se encontraba por debajo del pueblo, implicaba reubicar a los pobladores y excavar en una parte considerable de los terrenos agrícolas cultivados de frutas. Llevarse a cabo esto significaba transformar la cultura local ${ }^{10}$.

Por otro lado, en el conflicto también está en juego el interés económico al ser la agricultura la principal fuente de trabajo y de ingresos para los pobladores; los siguientes testimonios nos ofrecen esta idea:

"La agricultura de nosotros es una agricultura permanente...es una característica importante. Y, como le digo, le da una estabilidad de trabajo a la gente y económica. Usted no encuentra en Tambogrande de que hay niños mendigos, que hay gente tirada, allá el que no quiere trabajo es por flojo. Allá hay trabajo... a la gente no le falta por lo menos sus 20 soles en el bolsillo".

“... en el caso especifico de Tambogrande es que le quiso imponer una actividad minera... [La cual]... iba en perjuicio totalmente de nosotros porque Tambogrande es un caso especifico en el Perú, es un valle fértil, con una agricultura moderna de agroexportación y agroindustria".

“... [Hemos] desarrollado muy bien la agricultura moderna, los mangos de nosotros se va, pues, a Europa, Asia, EE.UU. Entonces si nosotros permitíamos la actividad minera, ya prácticamente matábamos toda la agricultura..."11

9 Luis Río Franco, agricultor y dirigente campesino de Tambogrande. Entrevistado en septiembre del 2005.

10 A nivel nacional, tanto organizaciones campesinas como la CONACAMI, los campesinos e investigadores, mencionan la transformación en la cultura local que implica la llegada de la mina. Así en el trabajo de Gouley, quien estudia el conflicto minero en Las Bambas, se puede ver que en los discursos de los dirigentes campesinos de la Federación Campesina de Cotabambas, la mina representa una amenaza a la cultura andina local porque puede introducir los "efectos perniciosos de la cultura occidental moderna y del capitalismo neoliberal". (Gouley 2005: 79). La misma autora hace notar que con la llegada y con la inclusión de ciertos grupos de campesinos en los puestos de trabajo de la mina, se corre el riesgo de excluir de la red de parentesco y solidaridad que unen a los campesinos en su comunidad. El sistema de reciprocidad practicado en la comunidad se pondría en riesgo al trabajar los campesinos en la mina por un salario, dejándose de lado las labores agrícolas y el cumplimiento de las obligaciones comunales (como la faena). Ante esta situación los comuneros enfrentan el problema para insertarse en la lógica del mercado laboral de la mina sin perder sus vínculos con sus tierras y comunidad (Ibídem, p. 57).

11 Luis Río Franco, entrevistado en septiembre del 2005. 
Estos testimonios revelan el valor económico que tiene la agricultura para los campesinos. Entonces, ¿qué tanta significación, expresada en términos económicos, ha tenido la agricultura en Tambogrande a fines del ' 90 e inicios del presente siglo? Para responder a la pregunta, es necesario mencionar que la actividad agrícola en el valle de Tambogrande se ha desarrollado históricamente gracias a un proyecto de irrigación auspiciado y financiado por el Banco Mundial en la década del ' 50 . Con el proyecto se irrigó tierras estériles y se inició la colonización de San Lorenzo, entendida, según los diarios de la época, como "un proceso de asentamiento del hombre en la tierra como agricultor". Las tierras destinadas a la colonización fueron parceladas en lotes de 6 a 8 hectáreas y vendidas a colonos que llegaron a ser más de 5,700 , quienes se dedicaron al cultivo de arroz, mangos, limones, algodones, etc. (Romero 1982: 13). El proyecto de irrigación hizo productiva a Tambogrande y el valle de San Lorenzo (que comprende los distritos de Tambogrande y Las Lomas en la provincia de Piura y los distritos de Paismas y Suyo en la provincia de Ayabaca). Antes del proyecto, Tambogrande era un pequeño poblado con comunidades de economía de autosubsistencia, dado que no tenía terrenos fértiles y de irrigación. No obstante, luego, se convertiría en un valle agrícola importante en Piura y en el Perú, principalmente por la producción de limones y Mangos. Por ejemplo, según algunas fuentes del 2000, el mango en Tambogrande representaba algo más del $80 \%$ de la exportación nacional, con un valor aproximado de 12 millones de dólares por año. Mientras que el limón se producía 150 mil toneladas, por un valor aproximado de 24 millones de dólares por año (Revista Agraria, 2000). El cultivo de estos dos productos es importante en el valle de San Lorenzo, pues el 59\% de las hectáreas se destinan al cultivo de esos productos, frente al 30\% que se destina al cultivo de arroz (Aste 2003: 18). Además, en la producción de limón y mango en lo que va de 1994 a 1999, Tambogrande, a nivel de Piura, aportaba -respectivamente- el $66.3 \%$ y $58.5 \%$; y el $40.3 \%$ y $38 \%$ de la producción de esos mismos productos a nivel nacional (Aste 2003). Así mismo, la ubicación cercana a la ciudad de Piura y al puerto de Paita implica facilidades a los pobladores de Tambogrande para exportar sus productos. Así, a inicios del presente siglo, el $40 \%$ de mangos se exportaba al exterior obteniendo U\$ 25 a 30 millones (Ibídem, 2003).

Entonces, ante la ventaja económica que implicaba la agricultura de exportación, era de esperarse que los agricultores defendieran la actividad agrícola y rechazaran el proyecto minero de la empresa Manhattan, la que -al decir de los campesinos- en materia de oferta laboral se hallaba en desventaja ${ }^{12}$.

Sintetizando, podemos afirmar que el conflicto minero ocurrido en Tambogrande se debió a la centralización de la toma de decisión por el Estado peruano y, por ende, exclusión a la participación ciudadana sobre la viabilidad de la ejecución del proyecto minero. La centralización está expresada en la decisión del Estado de llevar a cabo el proyecto minero, sin tomar en consideración el particularismo cultural y económico local, como por ejemplo el de la ejecución de un proyecto de desarrollo basado en la agricultura ${ }^{13}$ que los campesinos defendieron porque formaba parte de su cultura y, económicamente, era la principal fuente de recursos económicos.

12 Por ejemplo, los campesinos mencionaban que la mina sólo daría 500 puestos de trabajos frente a los 16 mil que generaba la actividad agrícola.

13 Es necesario decir que este proyecto formaba parte de un "plan estratégico" de desarrollo que ha pasado desapercibido por la autoridad central de entonces. Según Gina Alvarado, en el caso de Piura, para inicios del presente siglo se contaba con un plan de desarrollo al 2010, en el cual se contempla a la agricultura como la actividad principal de la región. Además, existían otros planes estratégicos en el ámbito de algunas provincias del mencionado departamento. Sin embargo, agrega, "debido a la debilidad de las autoridades locales y la poca capacidad de negociación que estas tienen respecto de los presupuestos asignados, las acciones que estas puedan planificar se ven recortadas por un sistema centralista de toma de decisiones" (2002: 159). 
Entonces, en el conflicto minero de Tambogrande se puede observar dos lógicas y/o racionalidades diferentes entre la población y el Estado, incluido la empresa minera. Por el lado del Estado ${ }^{14}$, y también la empresa minera, al concebir el desarrollo con base industrial, la ejecución del proyecto minero vendría a ser la palanca del desarrollo local (Tambogrande) y, por lo tanto, debería llevarse a cabo por ser la fuente generadora de divisas, etc. Por el lado de la población, ésta tendría una concepción distinta del desarrollo que estaría basado en la agricultura, por ser parte de su sistema sociocultural y generadora de ingresos inevitables para el sustento de muchas familias campesinas.

\section{Algunos rasgos de los conflictos mineros}

A nivel general, podemos afirmar que uno de los rasgos de un conflicto minero es el enfrentamiento entre empresa minera y población campesina, quien tendría como recurso a la acción colectiva (movilizaciones, marchas, protestas) para enfrentarse a sus adversarios mejor equipados. Según Sidney Tarrow, las formas "contenciosas" de acción colectiva asociadas a los movimientos sociales tienen poder porque desafían a sus oponentes más poderosos, despiertan solidaridad y cobran significado en el seno de determinados grupos de población, situaciones y culturas políticas (1997: 20). Sin embargo, por el lado de la población, el hecho de contar como recurso a la acción colectiva, no le sitúa en una situación de ventaja frente al poder de las empresas, ya que entre ellas las relaciones de poder es asimétrica. Esto se debe comprender dentro de un contexto de "violencia estructural"15 dado que -siguiendo a Gouley- los conflictos mineros son "esencialmente" estructurales en el sentido de que, por un lado, se enfrentan lógicas -temporales y espacialesestructuralmente incompatibles y, por otro lado, se desarrolla en un contexto caracterizado por las necesidades básicas insatisfechas como la educación y salud, pobreza, desigualdad en el acceso a la información y a los recursos de poder e influencia.

Gouley menciona algunos rasgos comunes de los conflictos mineros a nivel global y nacional. En lo que es el primer nivel, países desarrollados (como Canadá y Australia), y los que se encuentran en vías de desarrollo (como los de América Latina, países del África, Asia, etc.), tienen el problema de conflicto entre empresa minera y población rural con algunos rasgos similares como: que los proyectos mineros se ubican en territorios de poblaciones vulnerables, asimetrías en las relaciones de poder, la incapacidad de los Estados para proteger los derechos de sus ciudadanos, fallas en los mecanismos participativos de consulta y decisión, un transfondo intercultural común relacionado con la problemática central de la afirmación de los derechos de los pueblos indígenas, dado que el derecho consuetudinario y el nacional reflejan a menudo concepciones distintas de los recursos naturales y su uso ( Gouley 2005: 20-22).

Algunos de estos rasgos se pueden presenciar en el nivel nacional, sobre todo la ausencia de mecanismos participativos de consulta y la incapacidad del Estado para proteger los derechos de sus ciudadanos. A estos habrían que agregar -siguiendo a Ivan Ormaechea- otros factores que reflejan los conflictos mineros en el Perú, como: el impacto de la contaminación real o potencial, expectativas no satisfechas de la población en cuanto a las posibilidades de poder aprovecharse de los beneficios de la minería, procesos de diálogo y comunicación inadecuados, perspectivas culturales distintas sobre los valores asignados a los recursos naturales, altos grados de desconfianza entre los actores, visiones

14 Al decir de Orlando Plaza, nutrido de una concepción desarrollista de tipo industrial que ignora la realidad campesina y agraria (Plaza 1990: 223, 227).

15 Esto es un aporte de Johan Galtung (1996) que es cogido por Clotilde Gouley para comprender y explicar el conflicto minero suscitado en Las Bambas, Apurímac, en el periodo 2003-2004. 
incompatibles del desarrollo sostenible y la incompatibilidad entre la actividad agraria y minera (Ormaechea 2005: 177, 178, citado por Gouley 2005: 20).

De los rasgos señalados, rescataremos la asimetría de poder y las perspectivas culturales distintas.

Por un lado, el primero se expresaría en las relaciones entre los actores involucrados, principalmente empresas mineras (que representarían entidades poderosas que pueden influir en las políticas del Estado) y comunidades, las que aparecerían en una situación de desventaja frente a aquellas y el Estado, sea por la limitación en el acceso a la información, la comprensión y el manejo de la misma, ya que los textos técnicos sobre minería son de difícil entender por una persona no experta. Según Gouley, las comunidades no siempre disponen del asesoramiento necesario para descifrar el lenguaje técnico de los textos, lo cual constituye un límite al ejercicio de sus derechos ciudadanos y a la participación efectiva en la toma de decisiones (2005: 75). Para el caso del conflicto minero en Las Bambas, el límite al ejercicio de la ciudadanía se ve reflejado en el tema del DNI. Para los miembros de la empresa Xstrata, son ciudadanos todos los que tienen DNI y por lo tanto son estas personas las que deben de tener el derecho de trabajar en la mina en calidad de minero; en cambio, para los campesinos, deberían gozar el derecho de trabajar en la mina todos los comuneros que cumplen con sus obligaciones comunales. Entonces, en los conflictos mineros se evidencian las deficiencias del ejercicio de la ciudadanía en el Perú, así como la posición de desventaja de las comunidades frente a las empresas mineras y el Estado ${ }^{16}$. Esta última situación la podemos comprender graficando la figura de una pirámide invertida en la que las comunidades se ubicarían en una posición inferior, manteniendo una relación vertical con el Estado y las empresas mineras, quienes - por el contrario- estarían en una posición superior estableciendo - al mismo tiempouna relación de tipo horizontal entre sí.

\section{Empresas \\ Mineras}

\section{Relación de tipo horizontal}

Estado

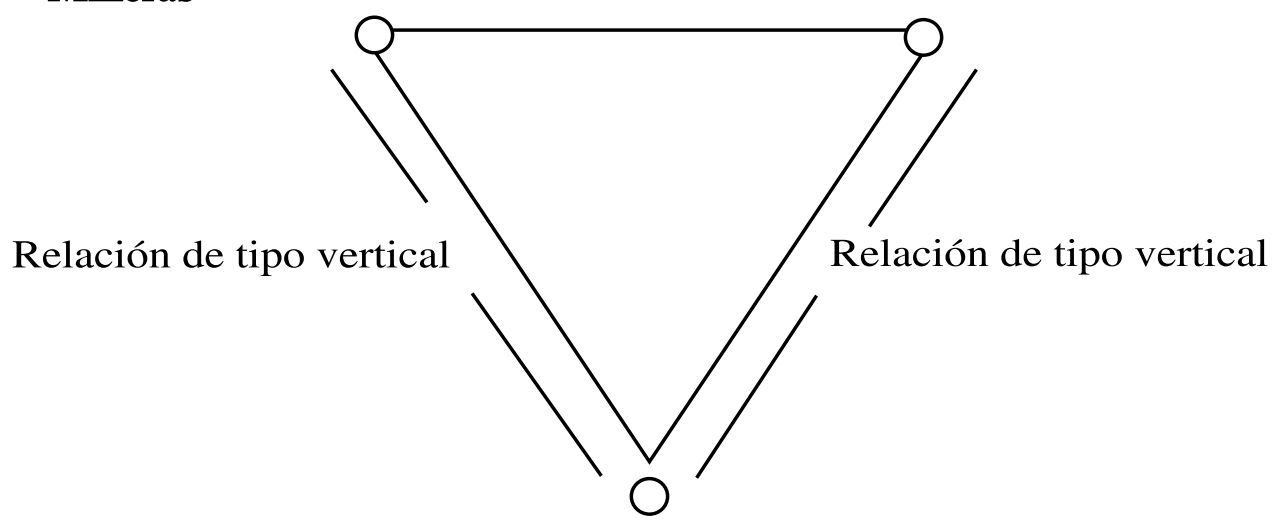

\section{Comunidades}

Podemos decir que en el triángulo existen tres ejes de comunicación y de relación con diferentes niveles de confianza y "flujos de información": 1) entre las empresas mineras y el Estado, 2) Estado y comunidades y, 3) empresas mineras y comunidades. Éstas últimas son las que reciben una inadecuada o muy limitada información, la cual dificulta las

16 Según Gouley, el conflicto entre comunidad y Estado es latente, no visible; mientas que entre comunidad y empresa minera, es visible. 
posibilidades equilibradas de negociación con las empresas mineras. Por ejemplo, para el caso del conflicto en Las Bambas, la población en algún momento se sintió "huérfana" (abandonado) o excluida del acceso a la información sobre el proyecto minero, por lo que expresaba su demanda de ser más informada.

Por otro lado, la presencia de perspectivas culturales distintas en relación a la percepción, por ejemplo, del desarrollo (caso Tambogrande) dan cuenta de la problemática cultural en los conflictos mineros. Clotilde Gouley lo detalla muy bien para el caso del conflicto minero en Las Bambas; según ella, en los proyectos mineros en el Perú se cruzan dos universos socioculturales ${ }^{17}$ : el andino y el moderno occidental, con distintas formas de aprender el trabajo, de percibir el medio ambiente y el tiempo (2005: 30). En el lado andino, están las comunidades y, en el occidental, las empresas mineras y el Estado, cada una de ellas con formas particulares de cultura. Así, en lo que se refiere a la cultura y a la percepción del medio ambiente, tenemos que:

a) Las empresas mineras. Un aspecto cultural de estas se puede percibir en sus diferentes normas y políticas de gestión. Según Gouley, tendrían a concebir el medio ambiente como fuente de minerales que van a asegurar, por su producción y comercialización, la expansión económica de las empresas. Es decir, los recursos mineros al ser mercancía, tienen un valor de uso y cambio (2005: 45).

b) El Estado. Tiene una cultura propia constituida por sus políticas, leyes, normas, etc. El Estado lleva consigo paradojas e incongruencias ${ }^{18}$. Según Gouley, tiene un posicionamiento ambiguo en los conflictos mineros. Aparece como actor y garante de un marco institucional y legal que protege los derechos de todos los ciudadanos (2005: 45). Al asumir el proceso de globalización económica y el modelo neoliberal mediante las políticas públicas, el Estado estaría inmerso en la "cultura occidental" en la que el medio ambiente es percibido como un objeto externo, "medible" y "explotable".

La legislación establece que el Estado tiene el dominio absoluto, inalienable e imprescriptible sobre las minas y considera, además, el desarrollo de la minería de interés público o social. De la misma manera, encarna una concepción del derecho ambiental que contrasta con la concepción de los recursos naturales de los campesinos quienes consideran que las tierras les pertenecen desde sus antepasados (Gouley 2005: 47). Aquí está presente el problema de disputa por el derecho de propiedad del subsuelo entre el Estado y la comunidad. La constitución política peruana de 1993 establece que el Estado es propietario del subsuelo y, por lo tanto, de los yacimientos de recursos naturales no renovables como los minerales. Por el contrario, desde la perspectiva de la comunidad, separar el subsuelo del suelo no tiene mucha significación, ya que "el territorio es un conjunto de recursos interrelacionados" (Ibídem p. 68).

17 De esta misma manera de pensar es Juan Ossio quien afirma el hecho de encontrar "entidades" que provienen de dos realidades diferentes: la empresa minera, "producto del sistema capitalista", y la población campesina "cuyo conocimieto de la realidad del mundo que se globaliza es algo desconocido" (Ossio 1994: 87)

18 Por ejemplo considera en la constitución política que todas las personas son iguales ante la Ley, pero en la práctica la relación entre el Estado y la población es de tipo excluyente, discriminatorio. En el caso de las legislaciones, leyes y decretos formuladas por el Estado, contienen varias incongruencias respecto a la promoción de la actividad agrícola y minera. Por una parte, según el artículo $88^{\circ}$ de la Constitución Política del Perú, el Estado debe apoyar preferentemente el desarrollo agrario y garantizar el derecho de propiedad sobre la tierra ya sea en forma privada o comunal. Por otro lado, según el Decreto Legislativo $N^{\circ}$ 653, Ley de Promoción de las Inversiones en el Sector Agrario, es prioritario el desarrollo integral del sector agrario y corresponde al Estado promover el eficiente uso de las tierras y las aguas. Sin embargo, tanto el artículo como el decreto mencionado, no son considerados cuando el Estado, mediante la legislación, promueve la actividad minera como principal, considerando de necesidad pública la inversión privada extranjera -como la de la empresa minera Manhattan-, lo cual contradice el artículo de la constitución en el que se prohíbe que dentro de los 50 kilómetros de la frontera, los extranjeros no pueden adquirir ni poseer minas. 
c) Las comunidades. El usufructo económico de los recursos naturales sería ajeno a la "cultura andina", pues para el "hombre andino" "el mundo estaría vivo y animado". Es así que, en algunas áreas ${ }^{19}$, consideraría a los cerros como sus apus, espíritus de montañas, con los cuales mantendrían relaciones de intercambio, mostrarían respecto (con los ritos y pagos) y pedirían favores especiales (Gouley 2005: 45). Esta forma de concebir está presente en las comunidades pertenecientes a las áreas denominadas andinas, como las del centro y sur del Perú (Ayacucho, Apurímac, Huancavelica, Cusco); pero, también, en áreas altoandinas del norte. Por ejemplo, en Huancabamba (Piura), zona con influencia minera, el antropólogo Sabino Arroyo identifica al Chikwate Grande (montaña sagrada y paqarina más elevada de la región de Huancabamba alta) que es considerado como una divinidad que puede castigar con sequías a la población, si es que esta no realiza el pagapu (ver más en Arroyo 2004).

En síntesis tenemos dos maneras de concebir el medio ambiente: en el moderno occidental, es mercancía con valor de uso y cambio; y, en el universo andino, los recursos -como las tierras agrícolas, cerros- son animadas, sin ser objeto de mercancía. Por supuesto que esto no es generalizable, como a las áreas de la costa.

\section{Reflexión sobre el manejo de los conflictos mineros}

Entonces, ¿cómo manejar un conflicto minero, en medio de situaciones como la asimetría tanto de poder como en el acceso a la información y perspectivas culturales distintas entre los actores? Según Gouley, en la teoría de la resolución de conflictos, el libro de Roger Fisher y William Ury, Getting to yes: Negotiating Agreement Without Giving it, se ha convertido en una referencia como modelo de resolución y negociación, sus principios básicos se han utilizado en procesos de negociación de negocios internacionales, relaciones internacionales y, también, se ha aplicado como marco explicativo para los conflictos mineros y ambientales (2005: 10). El modelo presupone que un buen acuerdo debe satisfacer los intereses de ambas (o más) partes y, por lo tanto, se fundamenta en la distinción entre las posiciones, que vendría a ser las expresiones de lo que los actores quieren obtener o evitar, y los intereses que son las razones que explican el por qué los actores defienden o adoptan una determinada posición (Gouley 2005: 10). De esta manera, Fisher y Ury consideran que las negociaciones deben estar basadas en los intereses antes que en las posiciones, dando a entender que en los conflictos se hallan intereses negociables que podrían transformarse en una situación de ganancia mutua. Sin embargo, esta teoría no deja de ser criticable por ser modelo ortodoxo de negociación y, cuando aplicado al manejo de conflictos socioambientales, la definición de intereses, en términos exclusivos de costo / beneficio, no deja mucho espacio al aspecto cultural, que para nosotros es importante. Mas aún cuando en los conflictos mineros, en algunas áreas del Perú ${ }^{20}$, se cruzan dos universos culturales con determinados rasgos culturales: "el andino" y "el moderno occidental"21, entre los que se hace necesario el diálogo. En este sentido, nuestra propuesta, para el manejo de un

19 Decimos esto para no generalizar prácticas culturales -como el respeto a los apus- a todas las comunidades, pues estas son diversas en todo el Perú. Así, el considerar a los apus como espíritu de montaña y a la tierra como la pachamama (madre tierra), si bien pueden estar presentes en algunas comunidades pertenecientes a las áreas tradicionalmente andinas -como Apurimac, Ayacucho, Huancavelica, Cusco, etc.-, en otras, en cambio, pueden estar ausentes. Estas serían áreas de la costa, como Tambogrande, en donde no se podría identificar las prácticas culturales mencionadas, por estar más influenciada por el mercado, con una agricultura de exportación. En este caso el panorama sería distinto a las áreas altoandinas.

20 Decimos esto por no ser generalizable a las otras áreas donde se ha desarrollado un conflicto minero. Por ejemplo, en el distrito de Tambogrande, por ubicarse en un área geográfica diferente, no se puede decir que sus pobladores, a pesar de ser agricultores campesinos, pertenecen a una "cultura andina", como los de las zonas altoandinas de Apurímac, Cuzco, Cerro de Pasco, la sierra de Piura, circunscritas a las actividades mineras.

21 En el primero, estarían las comunidades y, en el segundo, las empresas mineras y el Estado. 
conflicto minero, se dirige por el diálogo intercultural ${ }^{22}$. Es decir, diálogo "entre culturas" de grupos diferentes, ${ }^{23}$ que implica relación, intercambio, comunicación y aprendizaje los "unos" y los "otros", con el fin de comprender las particularidades de cada uno y llegar a un acuerdo mutuo en la resolución de un problema.

El diálogo intercultural constituiría un reto para los actores, en el sentido que exige ciertas condiciones ${ }^{24}$ como: 1) relaciones de simetría entre los actores e igual acceso a la

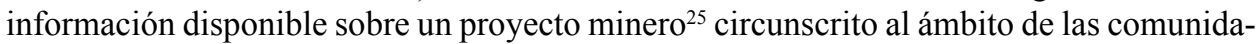
des, 2) conocimiento adecuado, con prácticas de respecto y tolerancia recíproca los "unos" y los "otros", 3) reconocimiento recíproco ${ }^{26}$ y estar dispuesto a aprender culturalmente los "unos" y los "otros" y, 4) reconocimiento del "otro"(campesino) como sujeto con derecho a decir, por ejemplo, su opinión y a ser escuchado.

La pregunta es, si los que tienen el poder económico (empresas mineras) y político (Estado) están dispuestos y preparados para asumir dichas condiciones, necesarias para el diálogo intercultural, el cual puede permitir que se mejoren las relaciones entre los actores y que se erosionen los espacios de comunicación fragmentados, tal como se muestra en la figura del triángulo invertido. Sin embargo, si no se crean las condiciones antes planteadas, el diálogo puede no ser tan suficiente y eficiente.

Entonces, el tema de la interculturalidad ${ }^{27}$ representa un desafío tanto para los miembros de las empresas mineras, quienes deberían de incluirlo en sus programas y políticas, como para el Estado, para quien la interculturalidad debería de ser un principio normativo que debe ser integrada en el diseño de las políticas públicas. Creemos que debe ser considerada en el manejo de los conflictos mineros, los que -al decir de Gouley-, como el caso de Las Bambas, reflejan los retos de la interculturalidad como proyecto político y su interrelación con el concepto de participación ciudadana ${ }^{28}$ (2005: 8).

22 El prefijo “inter” implica relación entre dos culturas. Según Xavier Etxeberria, en la interculturalidad lo importante es el diálogo "entre culturas", aunque esto presupone el respeto mutuo y condición de igualdad entre quienes dialogan. En esto último es que -al decir del autor- la interculturalidad reasume parte de la propuesta del multiculturalismo (2001: 18).

23 En una disertacion sobre comunidades y mineria, Ossio menciona el problema de la "comunicacion intercultural" entre la poblacion y las empresas mineras, pues "unos estan sumidos en su propia cultura sin preocuparse de los aspectos sociales, sino en su actividad productiva; y las poblaciones rurales se han desenvuelto en una tradicion cultural distinta" consistente en el idioma, vestimenta, creencias, etc. ( Ossio 1994: 87).

24 Para hacerlo posible se requiere trabajar por transformar las desigualdades sociales existentes.

25 Consideramos que el igual acceso a la información es fundamental para la prevención y el manejo de un conflicto minero. Y al parecer poner la información al alcance de la población, es la que mas rápidamente pueden hacer las empresas mineras, por que, de lo contrario, se verían deslegitimadas por falta de transparencia y descuidar la participación ciudadana. Además, hay un reglamento de participación ciudadana mediante el procedimiento de Audiencias Públicas, en el que se establece la presentación de los estudios ambientales ante las autoridades y población en general. En teoría, las audiencias constituyen un avance en la participación de la población y en la democratización de los informes sobre los proyectos mineros, pero, como arguye Alvarado, no son mecanismos de toma de decisión, sino de consulta (2002, p. 170). Aquí hay una discrepancia sobre la noción de este término: en el caso del conflicto en las Bambas, Gouley afirma que para la población local se refiere el derecho a participar en la decisión vinculada a las industrias extractivas en su territorio; en cambio, para el gobierno, la consulta es considerada en su noción más restringida de participación ciudadana, quedando la potestad de decisión al Estado (2005, p. 87).

26 Hay que decir que uno de los actores puede no llegar a reconocer al "otro" como sujeto con plena existencia. Así, cuando el Estado no consulta a la población sobre la ejecución de un proyecto minero, conlleva a pensar que no reconoce su existencia en un área con recursos mineros.

27 Tradicionalmente la interculturalidad ha estado relacionado con los temas educativos, creemos que, también, debe ser incluido para el manejo de conflictos sociales, para nuestro caso el originado por las industrias extractivas.

28 Promover la participación plena y efectiva de las comunidades en la decisión que afecta sus territorios y en los proyectos de desarrollos en la que están involucrados, es un tema pendiente y un derecho colectivo de las poblaciones. Respecto a esto, el Banco Mundial planteó el principio de "consentimiento libre, previo o informado de los pueblos indígenas para prevenir los conflictos generados por la actividad extractiva de 


\section{Referencias bibliográficas}

ARROYO, Sabino

2004 Dioses y oratorios andinos de Huancabamba. Lima, UNMSM.

ALVARADO, Gina

2002 "Recursos naturales y políticas públicas en el conflicto agrominero de Tambogrande" en Manuel Pulgar Vidal, Eduardo Zegarra, y Jaime Urrutia (Editores).

ASTE, Juan Perú: El problema agrario en debate. Sepia IX. Lima, Sepia, pp. 148-176.

2003 “Tambogrande y sus alternativas". Ponencia presentada en el Foro Público realizado en el Congreso de la República el 30 de junio. Lima

2002 Valor económico del valle de San Lorenzo. Tambogrande - Piura. Lima, CONACAMI/Mesa Técnica de Tambogrande.

\section{CEPES}

2003 La revista agraria. Año 4, N. ${ }^{\circ} 49$.

DE ECHAVE, José y TORRES, Víctor

2005 Hacia una estimación de los efectos de la actividad minera en los índices de pobreza en el Perú. Lima, Cooperación.

ETXEBERRIA, Xabier

2001 "Derechos culturales e interculturalidad" en María Heise (compiladora y editora) Interculturalidad, creación de un concepto y desarrollo de una actitud. Lima, Programa FORTE-PE. Ministerio de Educación, pp. 17-38.

GOULEY, Clotilde

2005 Conflictos mineros, interculturalidad y políticas públicas. El caso de Las Bambas, provincias de Cotabambas y Grau, departamento de Apurímac. Cusco, Centro Bartolomé de Las Casas / Consorcio de Investigación Económica y Social.

OSSIO, Juan

1994 "Minería y comunidades" en Alberto Pasco-Font, Carlos Chirinos y otros Mineria y comunidades. Lima, CooperAcción.

PLAZA, Orlando

1990 "Cambio Social y Desarrollo Rural” en Alberto Chirif y otros. Perú: El problema agrario en debate. Sepia III. Lima. Centro de Estudios Rurales Andinos Bartolomé de las Casas/Sepia.

ROMERO, Enrique

1982 “Colonización San Lorenzo. Despegue agrario” en Correo (agosto).

TORRES, Dagoberto

1964 "Colonización San Lorenzo" en El Comercio, Sección El Dominical (diciembre).

recursos naturales". Según Gouley, convertir este principio en un marco legal obligatorio podría constituir un avance significativo para la protección del derecho de todos los ciudadanos y, por tanto, para la prevención de conflictos mineros en el Perú. Así mismo menciona que la implementación de esta herramienta, que confiere mayor poder de decisión a las poblaciones locales sobre el destino de su territorio, requiere una reorientación de las políticas publicas peruana y una redefinición de las funciones y el rol del Estado (2005, p. 88). En esta parte habría que agregar el mecanismo de consulta reconocido por el Convenio 169 de la OIT en su articulo 15, al decir que si los recursos del subsuelo pertenecen al Estado, los gobiernos deberán establecer procedimientos adecuados con miras a consultar a los pueblos involucrados, a fin de determinar si los intereses de esos pueblos serian perjudicados, y en qué medida, antes de emprender cualquier programa de prospección y explotación de los recursos existentes. Este procedimiento de consulta al parecer no es considerado por el Estado peruano cuando se tienen previsto llevar a cabo la ejecución de un proyecto minero en los territorios de las comunidades. Entonces para que se cumpla el mecanismo de consulta, como afirma Gouley, se requiere una reorientación de las políticas públicas y repensar en el rol y funciones del Estado. 
TARROW, Sidney

1997 El poder en movimiento. Los movimientos sociales, la acción colectiva y la política. Madrid, Alianza Editorial.

ZÁRATE, Patricia; DURAND, Anahí

2005 "El desarrollo a la vuelta de la mina: percepciones sobre desarrollo, pobreza y minería" en Roxana Barrantes y otros: "Te quiero pero no": minería, desarrollo y poblaciones locales. Lima, IEP / OXFAM América. 